\title{
Iron Status and Coronary Risk in Rheumatic Heart Children
}

\author{
Azza M.A. Abul-FADL ${ }^{1}$ and Sahar Y. Al-OKBI ${ }^{2, *}$ \\ ${ }^{1}$ Paediatric Department, Benha University, Cairo, Egypt \\ ${ }^{2}$ Food Science and Nutrition Department, National \\ Research Centre, Giza, Egypt
}

(Received July 5, 1990)

\begin{abstract}
Summary This study aimed at clarifying the relationship between iron status and atherogenic lipid profile in normal and chronic rheumatic heart as well as congenital heart defect children. The study included 31 children, 16 cases with chronic rheumatic heart disease (10 males and 6 females) and 6 with congenital heart disease. Nine children with normal hearts were taken as the control. Serum iron and total iron binding capacity were higher in both chronic rheumatic and congenital heart disease children than in the controls; but the increase was only significant in the second case. Serum low-density lipoprotein cholesterol (LDL-ch) and high-density lipoprotein-cholesterol (HDL-ch) were not significantly changed in either disease. In relation to sex, no significant changes were noticed in iron status of chronic rheumatic heart children. Serum LDL-ch and LDL-ch to HDL-ch ratio were significantly higher in females than in males. A correlation study was also done between lipid profile and iron status.
\end{abstract}

Key Words: rheumatic heart, congenital heart, serum iron, lipoproteins, children

In recent years there has been growing interest in the risk factors predisposing to coronary heart disease. Although studied intensively, the problem seems to bear a different perspective in developing countries. Sullivan [1] reported that cardiovascular disease seems to be an inevitable concomitant of prosperity and that poverty protects the heart. However, others [2] presented evidence that children of low socio-economic areas had the most unfavourable risk factor profile for coronary heart disease. Two of the commonest medical problems in Egypt are malnutrition [3] and parasitosis [4] and are commonly associated with iron

*To whom correspondence should be addressed. 
deficiency anaemia. Sullivan [1] suggested that there is a definite relationship between iron status and heart disease risk based on the following observations: myocardial failure in patients with iron storage diseases [5], the accumulation of stored iron with age in men after adolescence and the accumulation of stored iron after menopause or hysterectomy with a two-fold increase in heart disease [6]. So that it is unlikely that estrogen alone could be responsible for the sex differences in heart disease.

The above data, in addition to the conflicting issue of the relationship of nutritional status to coronary risk, prompted us to uncover some facts pertaining to the iron status in our community and the atherogenic lipid profile in normal children and in children affected with chronic rheumatic as well as congenital heart disease.

\section{MATERIALS AND METHODS}

Twenty-two children aged 7 to 14 years, 16 cases with rheumatic heart disease and 6 with congenital heart disease, were selected from the Pyramids Rheumatic Heart Centre in Giza, Egypt. Nine age-matched controls with normal hearts were taken as a reference group. The 16 rheumatic heart cases consisted of 10 males and 6 females and included 8 cases with double mitral valve lesion, 4 cases with mitral incompetence, 2 cases with mitral stenosis, and 2 cases with mitral incompetence and aortic incompetence. The cases did not show signs of activity, and were not receiving any medication apart from prophylactic long acting penicillin. The 6 congenital heart patients included 3 cases with congenital cyanotic heart disease and another 3 with ventricular septal defect.

Blood samples were drawn and serum was separated. Estimation of serum iron and total iron binding capacity was carried out as described [7, 8]. HDL-ch and LDL-ch were also determined as described [9-11].

Statistical analysis was performed by Student's $t$-test. A correlation study was also done between iron status (serum iron and total iron binding capacity) and lipid profile (LDL-ch and HDL-ch).

\section{RESULTS}

\section{Serum iron, iron binding capacity, and percentage saturation}

There was a significant $(p<0.05)$ increase in the serum iron of children with congenital heart disease $(19.78 \pm 2.360 \mu \mathrm{mol} / \mathrm{liter})$ when compared with the control value $(13.33 \pm 2.103 \mu \mathrm{mol} /$ liter $)$. Total iron binding capacity was also significantly higher $(p<0.01)$ in congenital heart patients $(144.68 \pm 11.454 \mu \mathrm{mol} /$ liter) than in controls $(107.85 \pm 6.5 \mu \mathrm{mol} /$ liter $)$. Percentage saturation did not differ significantly between the two groups. In chronic rheumatic heart children, the mean serum iron $(15.87 \pm 1.665 \mu \mathrm{mol} /$ liter $)$, mean total iron binding capacity $(112.44 \pm 6.8 \mu \mathrm{mol} /$ liter $)$, and mean percent saturation $(15.12 \pm 1.925 \%)$ were in- 
creased, but not significantly so, over the values for the control patients (Table 1).

The percent saturation was below 16 (i.e., an indication of $\mathrm{Fe}$ deficiency anaemia) in 7 (77.78\%) of the control cases, 10 (62.5\%) of rheumatic heart disease children, and 4 (66.67\%) of congenital heart cases. So, of the 31 cases studied, 21 $(67.74 \%)$ of them showed biochemical evidence of Fe deficiency anaemia.

In relation to sex (Table 2), the serum iron and total iron binding capacity in chronic rheumatic heart children were higher in males $(16.89 \pm 1.983$ and $116.29 \pm$ $7.293 \mu \mathrm{mol} /$ liter, respectively) than in females $(14.18 \pm 2.834$ and $105.93 \pm 13.001$ $\mu \mathrm{mol} /$ liter, respectively), but these differences were insignificant $(p>0.05)$. The mean percentage saturation did not differ significantly: $15.69 \pm 2.587 \%$ for males and $14.17 \pm 2.752 \%$ for females.

Table 1. Comparison of serum iron, iron binding capacity, and \% saturation in control cases and in rheumatic heart and congenital heart children.

\begin{tabular}{llccc}
\hline & \multicolumn{1}{c}{$\begin{array}{c}\text { Serum } \\
\text { Fe } \\
(\mu \mathrm{mol} / \text { liter })\end{array}$} & $\begin{array}{c}\text { Total iron } \\
\text { binding capacity } \\
(\mu \mathrm{mol} / \mathrm{liter})\end{array}$ & $\begin{array}{c}\text { Saturation } \\
(\%)\end{array}$ \\
\hline Control & $n=9$ & $13.330 \pm 2.013$ & $107.850 \pm 6.500$ & $12.660 \pm 2.033$ \\
Rheumatics & $n=16$ & $15.870 \pm 1.665$ & $112.440 \pm 6.800$ & $15.120 \pm 1.925$ \\
Congenital heart & $n=6$ & $19.780 \pm 2.360^{*}$ & $144.680 \pm 11.454^{* *}$ & $13.460 \pm 0.972$ \\
\hline
\end{tabular}

Values significantly different from the control: ${ }^{*} p<0.05 ;{ }^{*} p<0.01$.

Table 2. Sex differences in serum iron, total iron binding capacity (TIBC), \% saturation, LDL-ch, HDL-ch, and LDL-ch : HDL-ch ratio in rheumatic heart patients.

\begin{tabular}{lcc}
\hline & $\begin{array}{c}\text { Male rheumatic } \\
\text { heart children } \\
n=10\end{array}$ & $\begin{array}{c}\text { Female rheumatic } \\
\text { heart children } \\
n=6\end{array}$ \\
\hline Iron $(\mu \mathrm{mol} /$ liter $)$ & $16.890 \pm 1.983$ & $14.180 \pm 2.834$ \\
TIBC $(\mu \mathrm{mol} / \mathrm{liter})$ & $116.290 \pm 7.293$ & $105.930 \pm 13.001$ \\
Saturation (\%) & $15.690 \pm 2.587$ & $14.170 \pm 2.752$ \\
LDL-ch (mmol/liter) & $1.450 \pm 0.168$ & $2.830 \pm 0.184^{* *}$ \\
HDL-ch (mmol/liter) & $0.840 \pm 0.164$ & $0.630 \pm 0.133$ \\
LDL-ch : HDL-ch ratio & $1.800 \pm 0.563$ & $5.300 \pm 0.853^{*}$ \\
\hline
\end{tabular}

Values significantly different from corresponding male value: ${ }^{*} p<0.005 ;{ }^{*} p<0.0005$.

Table 3. Comparison of lipid profiles; LDL-ch, HDL-ch, and LDL-ch : HDL-ch ratio in controls, rheumatic heart and congenital heart children.

\begin{tabular}{llccc}
\hline & $\begin{array}{c}\text { HDL-ch } \\
(\mathrm{mmol} / \mathrm{liter})\end{array}$ & $\begin{array}{c}\text { LDL-ch } \\
(\mathrm{mmol} / \mathrm{liter})\end{array}$ & $\begin{array}{c}\text { LDL-ch : HDL-ch } \\
\text { ratio }\end{array}$ \\
\hline Control & $n=9$ & $0.570 \pm 0.060$ & $2.120 \pm 0.230$ & $3.900 \pm 0.457$ \\
Rheumatic hearts & $n=16$ & $0.760 \pm 0.118$ & $1.970 \pm 0.210$ & $3.120 \pm 0.638$ \\
Congenital hearts & $n=6$ & $0.570 \pm 0.139$ & $2.040 \pm 0.433$ & $5.620 \pm 1.690$ \\
\hline
\end{tabular}

No values differ significantly from the control.

Vol. 9, No. 3, 1990 
Table 4. Correlative studies between LDL-ch or LDL-ch : HDL-ch ratio and iron, total iron binding capacity (TIBC), and percentage saturation in rheumatic heart patients of either sex.

\begin{tabular}{|c|c|c|c|c|c|c|c|}
\hline & & \multicolumn{2}{|c|}{ Iron } & \multicolumn{2}{|c|}{ TIBC } & \multicolumn{2}{|c|}{ Saturation (\%) } \\
\hline & & $\begin{array}{l}\text { Male } \\
n=10\end{array}$ & $\begin{array}{c}\text { Female } \\
n=6\end{array}$ & Male & Female & Male & Female \\
\hline LDL-ch & $r$ & 0.12 & 0.85 & 0.13 & -0.40 & -0.05 & 0.81 \\
\hline LDL-ch : HDL-ch ratio & $r$ & -0.42 & 0.77 & 0.13 & 0.07 & -0.35 & 0.43 \\
\hline
\end{tabular}

Table 5. Correlative studies of LDL-ch and LDL-ch : HDL-ch ratio with serum iron, total iron binding capacity (TIBC), and percentage saturation in control (C) cases and congenital heart patients (Cong.Hrt).

\begin{tabular}{|c|c|c|c|c|c|c|c|}
\hline & & \multicolumn{2}{|c|}{ Iron } & \multicolumn{2}{|c|}{ TIBC } & \multicolumn{2}{|c|}{ Saturation (\%) } \\
\hline & & $\begin{array}{c}\mathrm{C} \\
n=9\end{array}$ & $\begin{array}{c}\text { Cong.Hrt } \\
n=6\end{array}$ & $\mathrm{C}$ & Cong.Hrt & $\mathrm{C}$ & Cong.Hrt \\
\hline LDL-ch & $r$ & -0.57 & -0.26 & 0.31 & -0.54 & -0.57 & 0.54 \\
\hline LDL-ch : HDL-ch ratio & $r$ & -0.65 & 0.06 & -0.32 & 0.54 & -0.61 & -0.29 \\
\hline
\end{tabular}

\section{Lipid profile, $L D L-c h, H D L-c h$, and $L D L-c h: H D L-c h$ ratio}

As seen in Table 3, the HDL-ch mean serum levels in controls $(0.57 \pm 0.06$ $\mathrm{mmol} /$ liter $)$, rheumatic heart cases $(0.76 \pm 0.118 \mathrm{mmol} /$ liter $)$, and congenital heart cases $(0.57 \pm 0.139 \mathrm{mmol} /$ liter $)$ were not significantly different from one another $(p>0.05)$.

Nor were the mean serum levels of LDL-ch: controls, $2.12 \pm 0.23 \mathrm{mmol} / \mathrm{liter}$; rheumatic heart cases, $1.97 \pm 0.21 \mathrm{mmol} /$ liter and congenital heart cases, $2.04 \pm$ $0.433 \mathrm{mmol} / \mathrm{liter}(p>0.05)$. Thus the LDL-ch to HDL-ch ratio of either group did not differ significantly from that of the other.

In relation to sex, the mean serum LDL-ch was significantly higher $(p<$ $0.0005)$ in chronic rheumatic heart females $(2.83 \pm 0.184 \mathrm{mmol} /$ liter $)$ than in corresponding males $(1.45 \pm 0.168 \mathrm{mmol} / \mathrm{liter})$. Also, the LDL-ch to HDL-ch ratio was significantly higher $(p<0.005)$ in the females $(5.3 \pm 0.853)$ than in the males $(1.8 \pm 0.563)$. While the HDL-ch level in males $(0.84 \pm 0.164 \mathrm{mmol} /$ liter $)$ was not significantly higher than that in females $(0.63 \pm 0.133 \mathrm{mmol} /$ liter $)$ (Table 2).

\section{Correlative studies}

There were significant positive correlations between $\mathrm{Fe}$ and LDL-ch $(r=$ $+0.85, p<0.05)$, Fe and LDL-ch to HDL-ch ratio $(r=+0.77, p<0.05)$, and percent saturation and LDL-ch $(r=+0.81, p<0.05)$ in rheumatic heart patients of the female sex, but no significant relationships were seen between Fe and LDL-ch in the male sex (Table 4).

For controls, correlative studies between Fe and LDL-ch $(-0.57)$ and $\mathrm{Fe}$ and LDL-ch : HDL-ch ratio $(-0.65)$ were significant at $p<0.05$. The \% saturation with LDL-ch $(-0.57)$ and with LDL-ch to HDL-ch ratio $(-0.61)$ was also significant 
at $p<0.05$. No significant relationship was seen between serum $\mathrm{Fe}$ or $\%$ saturation and LDL-ch to HDL-ch ratio in congenital heart patients (Table 5).

\section{DISCUSSION}

This study reflects the high prevalence of iron deficiency anaemia in our community. According to Zilva and Pannall [12], percent saturation is a better index of iron deficiency anaemia than iron alone; and when it is below 16\%, iron deficiency is likely to be present. Accordingly we found iron deficiency to be commoner in the control cases (78\%) than in the cases with rheumatic heart (62\%) and congenital heart (67\%). Overall iron deficiency was a common feature in all the cases. In a survey carried out on Egyptian children [3], iron deficiency was found to affect an estimated 1.4 million. Said et al. [13] reported low haemoglobin mean levels in school-aged children. Abul-Fadl [4] found the serum iron level significantly reduced in children with parasitic infestation. Iron deficiency in heart disease is a serious finding. Iron deficiency anaemia induces cardiac hypertrophy with a defective mitochondrial population, potentially placing the heart in an energy imbalance [14].

In congenital heart patients the higher mean serum iron is due to the associated hypoxia, which enhances mucosal iron uptake by a mechanism that is independent of the stimulated erythropoiesis. Also, the changes in the rate of erythropoiesis have an additional effect, particularly on the transfer phase of iron absorption [15].

There was tendency for rheumatic heart disease children to show a higher mean serum iron and percent saturation than control cases. Although the nutritional status may be similar and the chronic disease process may further impair the absorption and utilization of nutritive elements, yet the lack of physical exercise may account for the differences encountered in the iron metabolism. Other studies $[16,17]$ have shown that iron deficiency anaemia develops more in active children. Rheumatic heart disease children may develop cardiac cirrhosis in which iron levels may be high [12].

Sex differences in chronic rheumatic heart patients were found in the serum iron and TIBC, both of which were higher in males. The difference is probably hormonal in origin and becomes evident around puberty before significant menstrual iron is lost. Androgens tend to increase plasma iron concentration; and estrogen tends to lower it [12].

On examining the correlation between the LDL-ch to HDL-ch ratio in the control group and their serum iron or percent saturation, we found a significant negative correlation. Thus, the iron deficiency in this group was accompanied by an increase in the LDL-ch to HDL-ch ratio; i.e., it encouraged an atherogenic profile. The anaemia may depress the metabolic processes affecting the conversion of LDL and HDL in the liver [18].

The lipid profile in the heart patients was comparable to that in the control

Vol. 9, No. 3, 1990 
group. However, the females with chronic rheumatic heart disease had a significantly higher LDL-ch and LDL-ch to HDL-ch ratio than the corresponding males. This unfavourable risk factor profile was also accompanied by significant positive correlations of the ratio with serum iron and percent saturation. This suggests that the atherogenic lipid profile in females is closely related to the iron status. A direct relationship between iron and heart disease has been suggested by Sullivan [1], who believes that the differences reported in coronary heart disease risk cannot be solely attributed to hormonal factors and that the increases in iron stores in the body may also play a role. His hypothesis is backed by the findings of other workers [19] of the equal incidence of coronary risk in men and women undergoing surgical menopause inspite of intact ovaries. However, we found no significant correlations between lipids and iron in males. The absence of such finding in males could be due to the protective effect of testosterone on the development of a lipid atherogenic profile prepubertally [20].

The relationship between atherosclerosis and iron can be explained by the hydroxyl radical formed in the process of transformation of iron from the ferric to ferrous form [21]. The hydroxyl radical is the most toxic of univalent reduction products derived from oxygen, and it is able to attack or destroy membranes [22]. Sparrow et al. [18] showed that LDL can be oxidatively modified by cultured endothelial cells or by cupric ions resulting in increased macrophage intake of lipoprotein. The oxidative powers of iron may mimic in the same way the effects of cupric ions. Hence the mechanism whereby iron is atherogenic could operate via the formation of macrophage-derived foam cells characteristic of early atherosclerotic lesions.

In conclusion, our findings indicate that although iron deficiency anaemia is common in rheumatic and congenital heart disease children, yet they appear to be better off than heart disease-free Egyptian children. Of considerable interest was the finding of significant positive correlations between the lipid profiles and serum iron and percent saturation. The risk of atherosclerosis, whose natural history starts from childhood, appears to be linked with both iron deficiency in heart disease-free subjects and iron level elevation in heart patients. Such findings urge us to be more cautious in prescribing iron to such patients. More studies should be directed towards defining the levels of iron in the body that would be biologically harmless.

The authors wish to thank Prof. Dr. Zahira H. Abdin, Pyramid Rheumatic Heart Centre, and Prof. Dr. O.M. Metwalli, Head of Food Science and Nutrition Dept., National Research Centre, Egypt, for the use of their facilities.

\section{REFERENCES}

1. Sullivan, J.L. (1981): Iron and the sex difference in heart disease risk. Lancet, 8233(i), 12931294.

2. Walter, H.J., and Hofman, A. (1987): Socioeconomic status, ethnic origin and risk factors 
for coronary heart disease in children. Am. Heart J., 113, 812-818.

3. Nutrition Institute and Centre for Disease Control (1978): "Nutrition status survey I" report to USAID Washington and $\mathrm{MOH}$, mimeo.

4. Abul-Fadl, M., Rashad, S., and Al-Mahrouky, L. (1986): Haemoglobin affection in parasitic infections among some inhabitants of the eastern delta Egypt. J. Egypt. Soc. Parasit., 16, $147-153$.

5. Leon, M.B., Borer, J.S., and Bacharach, S.L. (1979): Detection of early cardiac dysfunction in patients with severe beta-thalassaemia and chronic iron overload. N. Engl. J. Med., 301, $1143-1148$.

6. Kannel, W.B., Hjortland, M.C., McNamara, P.M., and Gordon, T. (1976): Menopause and the risk of cardiovascular disease. The Framingham Study. Ann. Intern. Med., 85, 447-452.

7. Williams, H.L., Johnson, D.L., and Haut, M.J. (1977): Simultaneous spectrophotometry of $\mathrm{Fe}^{2+}$ and $\mathrm{Cu}^{2+}$ in serum denatured with guanidine hydrochloride. Clin. Chem., 23, 237-240.

8. Piccardi, G., Nyssen, M., and Dorche, J. (1972): Determination du fer et de la capacité totale de fixation dans le serum human par une méthode sans deproteinisation. Clin. Chim. Acta, 40, 219-228.

9. Burstein, M., Scholnick, N., and Morfin, R. (1970): Rapid method for the isolation of lipoproteins from human serum by precipitation with polyanions. J. Lipid Res., 11, 583595.

10. Allain, C.C., Poon, L.S., Chan, C.S.G., Richmond, W., and Poul, C.F. (1974): Enzymatic determination of total serum cholesterol. Clin. Chem., 20, 470-475.

11. Gerard, T., and Gerald, A.L. (1981): Process and reagents for the selective separation of low-density lipoprotein (LDL) and for the quantification of their components. Eur. Pat. Appl. Ep., 76, 211-221.

12. Zilva, J.F., and Pannall, P.R. (1975): Clinical Chemistry in Diagnosis and Treatment (2nd ed.), Iloyd, Luke Ltd. Publ., London, pp. 396-405.

13. Said, A.K., El-Shafai, M.M., and Bassily, N.S. (1982): Health and nutritional status of adolescent girls in a Cairo native neighborhood. J. Egypt.Publ. Health Assoc., 57(2), 1-12.

14. Macdonald, V.W., and Jacobus, W.E. (1987): Substrate dependent functional defects and altered mitochondrial respiratory capacity in hearts from guinea pigs with iron deficiency anaemia. Biochem. Biophys. Acta Ser. Bioenerg., 891, 103-114.

15. Raja, K.B., Simpson, R.J., Pippard, M.J., and Peters, T.J. (1988): In vivo studies on the relationship between intestinal iron $\left(\mathrm{Fe}^{3+}\right)$ absorption, hypoxia and erythropoiesis in the mouse. Br. J. Haematol., 68, 373-378.

16. Gimenez, M., Uffhollz, H., and Paysant, P. (1988): Serum iron and transferrin during an exhaustive session of interval training. Eur. J. Appl. Physiol. Occup. Physiol., 57, 154-158.

17. Magazanik, A., Weinstein, Y., and Dlin, D.A. (1988): Iron deficiency caused by 7 weeks of intensive physical exercise. Eur. J. Appl. Physiol. Occup. Physiol., 57, 198-202.

18. Sparrow, C.P., Parthasarathy, S., and Steinberg, D. (1988): Enzymatic modification of low density lipoprotein by purified lipoxygenase plus phospholipase $\mathrm{A}_{2}$ mimics cell-mediated oxidative modification. J. Lipid Res., 29, 745-753.

19. Gordon, T., Kannel, W.B., Hjortland, M.C., and McNamara, P.M. (1978): Menopause and coronary heart disease. The Framingham Study. Ann. Intern. Med., 89, 157-161.

20. Idris, A., Abul-Fadl, A.M.A., Al-Okbi, S.Y., and Abdin, Z.H. (1989): Lipoproteinendocrine interaction and coronary risk in rheumatic heart disease, in Fourth International Congress on Pediatric Laboratory Medicine, Washington, D.C., August 20th-24th.

21. Blake, D.R., Hall, N.D., and Bacon, P.A. (1981): The importance of iron in rheumatoid disease. Lancet, 8256(ii), 1142-1144.

22. Willson, R.L. (1978): Free radicals and tissue damage: Mechanistic evidence from radiation studies, in Biochemical Mechanisms of Liver Injury, ed. by Slater, T.F., Academic Press, London, pp. 123-224. 